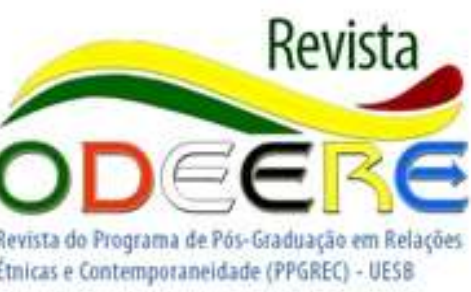

A continuação dos estudos sobre as escritas do memoriando: Atos de currículo e preconceitos revelados

\title{
Continuation of
} studies on the memoirs' writings: Curriculum acts and prejudices revealed

\author{
Zoraya Maria de Oliveira Marques \\ Universidade do Estado da Bahia \\ zmarques@uneb.br
}

DOI: 10.22481/odeere.v4i8.6237

RESUMO:

Este é o segundo texto produzido pela investigação de inspiração etnográfica 'Eu, Pedagoga' e busca revisar e dar seguimento a sistematização dos estudos e análises advindas da sua primeira etapa, apresentada no relato de experiências com o título "Questões étnico raciais no ato de currículo Memoriando: identidade(s) em conflito ou o silenciamento de si?". O conjunto de argumentos e posições aqui pontuadas, resultaram, por sua vez, do esforço de compreensão de 06 entrevistas tópicas que selecionamos de forma criteriosa junto aos estagiários da disciplina Pesquisa e Estágio em Espaços Não Escolares do Curso de Pedagogia, que relutaram, mas que terminaram se envolvendo com o desafio de colaborar com esta investigação.

Palavras-chave: Memoriando. Ato de Currículo. Questões Étnico Raciais.

\begin{abstract}
:
This is the second text produced by the ethnographic-inspired investigation 'Eu, Pedagoga' and seeks to revise and continue the systematization of studies and analyzes arising from its first stage, presented in the report of experiences with the title "Ethnic racial issues in the act of curriculum Memorizing: identity (s) in conflict or silencing oneself? ". The set of arguments and positions punctuated here resulted, in turn, from the effort to understand 06 topical interviews that we carefully selected with the trainees of the discipline Research and Internship in NonSchool Spaces of the Pedagogy Course, who were reluctant, but who ended up getting involved with the challenge of collaborating with this investigation.
\end{abstract}

Keywords: Memorizing. Curriculum Act. Ethnic Racial Issues. 
"... para nós, a idéia de existência se aplica também aos conjuntos humanos: grupos, comunidades, cultura e instituições, porquanto, são entidades habitadas e dinamizadas por sujeitos sociais (MACEDO)."

Este trabalho revisa e dá continuidade a sistematização de um dos estudos centrais que o Projeto de Experiências Criadoras (PEC)' desenvolveu durante a sua vigência (1995 a 2016) e que foi absorvido pelo Projeto UNEB nas Comunidades (UC'S) desde 2016. Logo no começo, a investigação formação já tinha a intenção de estudar quais elementos curriculares e produção de sentidos os Estagiários costumam relacionar, ao tratar de questões étnicas de origem racial enquanto cursavam o $5^{\circ}$ semestre do Curso de Pedagogia e no decorrer das suas itinerancias formativas.

Assim, a pesquisa intitulada: "Questões étnicas raciais no ato de currículo Memoriando': identidade(s) em conflito ou o silenciamento de si?" teve seu início com a produção do exercício didático conhecido como "Memoriando: Eu Pedagoga' que integrava o conjunto de publicações produzido pelo PEC e envolvia, por sua vez, as teorias e práticas propostas pela disciplina 'Pesquisa e Estágio em Espaços Não Escolares', sob a responsabilidade da própria pesquisadora ${ }^{2}$ e coordenadora geral do referido projeto.

Ora, como nos adverte Macedo3, num determinado cenário curricular, aprender é empoderar-se numa cultura densa, estruturante e opcionada onde, de modo relevante, o aprendizado e a formação apresentam um tipo de conhecimento.

Não causa estranheza, portanto, que os colaboradores da nossa pesquisa tenham sido selecionados a partir do critério da implicação identitária e do envolvimento com as questões curriculares do seu curso de Pedagogia, reveladas não apenas pelos seus posicionamentos, comportamentos e atitudes em sala de

\footnotetext{
1 É importante retomar que o Projeto de Experiências Criadoras (PEC) foi redimensionado há três anos, na ocasião em que deu lugar ao Projeto UNEB nas Comunidades (UC'S) de forma a ampliar seus ações e estudos junto a vivência de um currículo transversalizado que tem a pesquisa, o ensino e a extensão como dimensões indissociáveis do fazer/pensar/fazer uma universidade inclusiva e implicada.

2 Conforme previsto desde sua versão preliminar, este texto aprofunda os elementos estudados no Exercício 'Memoriando' cujas diferentes configurações e propósitos educativos integraram o acervo didático e pedagógico produzido pelo Projeto de Experiências Criadoras (PEC) ao longo de sua existência que compreendeu o período de 1995.2 à 2016.

${ }_{3}$ MACEDO, Roberto Sidnei. Compreender e mediar a formação: o fundante da educação. Brasília: Liber Livro, 2010.
} 
aula, mas também pelo envolvimento com a cultura e extensão acadêmica, através do Projeto UC'S em suas mais diferenciadas pautas e tensões socioculturais, e dentre elas as questões étnicas de origem racial.

Entretando, não foi simples trabalhar com tais histórias em seus complexos cenários curriculares subjetivos e relutâncias correspondentes. É que, nas primeiras tentativas não foi possível encontrar sujeitos que concordassem em participar como depoentes do estudo, considerando que, quando convidados recusavam delicadamente.

O explicativo era simples: o fato de que não poderiam se deixar identificar perante a comunidade interna, nem tampouco externa, sob o legitimo argumento de que não gostariam de ver expostas algumas de suas mais íntimas, e as vezes dolorosas, particularidades e vivências, ainda mais no meio do curso, já que estavam no $5^{\circ}$ semestre e poderiam ser identificados até pela própria turma em que estavam matriculados.

Daí que, a ferramenta metodológica especialmente constituída para a pesquisa acontecer, teve como preliminar seletiva o exercício 'Memoriando: Eu Pedagoga' que tinha por intenção provocar a estagiária e o estagiário a querer pensar mais detidamente acerca da sua existência em formação. Afinal, concordamos com Macedo 4 que é o sujeito que aprende, ele é quem compreende e quem atualiza no mundo suas aprendizagens.

Teria que partir delas e deles, portanto, a vontade de 'tocar' ou não, nas lembranças e memórias relacionais, e talvez até doídas, que o exercício provocaria e quem sabe, ao fazer isso, decidir se envolver com a pesquisa questionante e implicada que propunha o Projeto PEC.

Para estas adesões finalmente acontecerem, ajudou, sem sombra de dúvida, a garantia de anonimato que o termo de compromisso oferecia, o que preservava a privacidade e respeito ético junto a todas as narrativas provenientes das entrevistas tópicas, acima de qualquer outro aspecto.

\section{COMO ERA PROPOSTO O EXERCÍCIO 'MEMORIANDO: EU PEDAGOGA'}

A experiência começava com a proposição de um exercício vivencial, cuja

${ }^{4}$ MACEDO, Roberto Sidnei. Compreender e mediar a formação: o fundante da educação. Brasília: Liber Livro, 2010. 
preparação, e posterior apresentação em sala de aula, envolvia um planejamento cuidadoso e, consequentemente os respectivos organizativos materiais, que dessem maior visibilidade e clareza às narrativas individuais orais e autobiográficas que seriam compartilhadas conosco.

Ao entenderem que, teriam que expor algo pessoal sobre si mesmos perante seus colegas e professora da disciplina e que, para tanto, teriam que selecionar algum fato marcante em suas vidas, cujo impacto teria causado ou interferido, diretamente, numa mudança de rumo nas suas existências, a reação inicial era quase sempre de resistência.

O que não impedia, paradoxalmente, de demonstrarem curiosidade e súbita atração pela proposta, na medida em que indagavam: "e se concordassem, como isso seria feito? quanto tempo duraria? de que modo se apresentariam? e poderiam utilizar algum recurso? usar fotografias? preparar slides?" ou, mesmo indagavam "se tinham a opção de gravar um depoimento em vídeo, no lugar da exposição oral".

O debate acalorado e argumentações dos prós e contras, invariavelmente, levavam mais do que uma hora, seguido da leitura coletiva e nova conversa sobre o documento impresso e detalhado com o título "Memoriando" onde eram formuladas as especificidades do exercício quanto ao formato e conteúdo que seriam explorados individualmente.

A recomendação recorrente era sempre, que buscassem realizar mais do que uma mera atividade didática extrapolando assim o usual comum, onde as emoções, a coragem, a abertura ao inusitado e o uso dos sentidos fossem a principal inspiração das diversas linguagens artísticas à disposição.

O relato de um determinado acontecimento marcante em suas existências, que estaria assim vinculado ao que costumamos chamar de "divisor de águas" como uma linha invisível que tivesse separado suas vidas entre 'antes e depois de'.

Fosse na voz e palavras de Maria Betânia, essa sensação do depois de, seria: "pra que querer saber que horas são? se é noite ou faz calor, se estamos no verão, se o sol virá ou não, ou pra que é que serve uma canção como essa". Como se algo ficasse para trás, como se nada mais pudesse ser igual ao que tinha sido antes, tal a importância, impacto e mudanças causadas por este fato em questão.

Propositadamente, não havia indicação alguma, nas orientações do 
exercício, de que esperávamos ver emergir nos relatos alguns episódios de preconceito, ou de discriminação e intolerância. Tal expectativa silenciosa se justificava porque, afinal de contas, as narrativas envolveriam as mais diversas situações e pessoas perspectivadas em suas diferentes atitudes, reações, sentimentos, opiniões, crenças e comportamentos.

Ao contrário, porém, do esperado quase nenhuma das apresentações até o presente momento, nem mesmo nas narrativas das estudantes negras e dos estudantes negros 5 trouxe à tona, de forma explícita, argumentos discursivos que problematizassem questões étnico raciais ou outras discussões tão importantes quanto.

Tampouco, as teorizações na síntese escrita, que são produzidas eventualmente depois do exercício Memoriando, faziam referências ou ao menos alguma alusão a situações e episódios de exclusão e preconceito sofridos no dia a dia, no âmbito familiar, escolar, acadêmico, social, qual fosse.

Tratava-se, evidentemente, de uma fuga consciente ou não, uma recusa mesmo a deixar a zona de conforto oferecida pelas práticas curriculares habituais, para se aventurar num exercício do âmbito do desconhecido, numa oportunidade de forma detida e auto implicada acerca da própria existência e de seus acontecimentos formacionais.

Essa proposta, Macedó diria se tratar do ato de currículo que se dá de forma entretecida, de uma (in)tensa sensibilidade epistemológica, política e heurística pró-diferença. Ato de currículo que se materializa da ação concreta inserida no mundo vivido pelo sujeito, em caráter intencional porque situado.

Posteriormente, era para as estagiárias e estagiários afrodescendentes, que mais se envolveram e se aproximaram das intenções do Memoriando que encaminhávamos o convite para participarem das entrevistas tópicas.

Como esclarecido noutras sistematizações, a intenção era de provocá-los para refletirem "sobre os não ditos observados no que se referia às questões de etnia racial, uma vez que na apresentação do 'Memoriando' não explicitaram a existência de implicações e impactos causados em seus processos identitários, ou

\footnotetext{
${ }^{5}$ Nos estudos do Projeto PEC e do UC'S a palavra "negro" se vincula aos sentidos e representações construtivas e de valorização das questões étnicas e de afro descendência.

6 MACEDO, Roberto Sidnei. A Teoria etnoconstitutiva de currículo: teoria - ação e sistema curricular formacional. Curitiba: CRV, 2016.
} 
nem mesmo perceberam esta ausência nos currículos propostos"7.

Além do que, há uma sinalização que não pode ficar de fora: nunca houve sequer, por exemplos, em nenhuma das edições do Memoriando apresentadas por sujeitos negros uma simples alusão que fosse, a história da legislação brasileira no que se refere aos direitos da população negra onde o estudante se situasse. Aliás, vale destacar que finalmente hoje em 20 de novembro - Dia da Consciência Negra - durante a revisão desta escrita, fui surpreendida (em mais de um grupo whatsapp) pela postagem ${ }^{8}$ que traçava uma significativa sequência temporal:

Figura 01 - Linha de Tempo sobre as Leis e a População Negra no Brasil

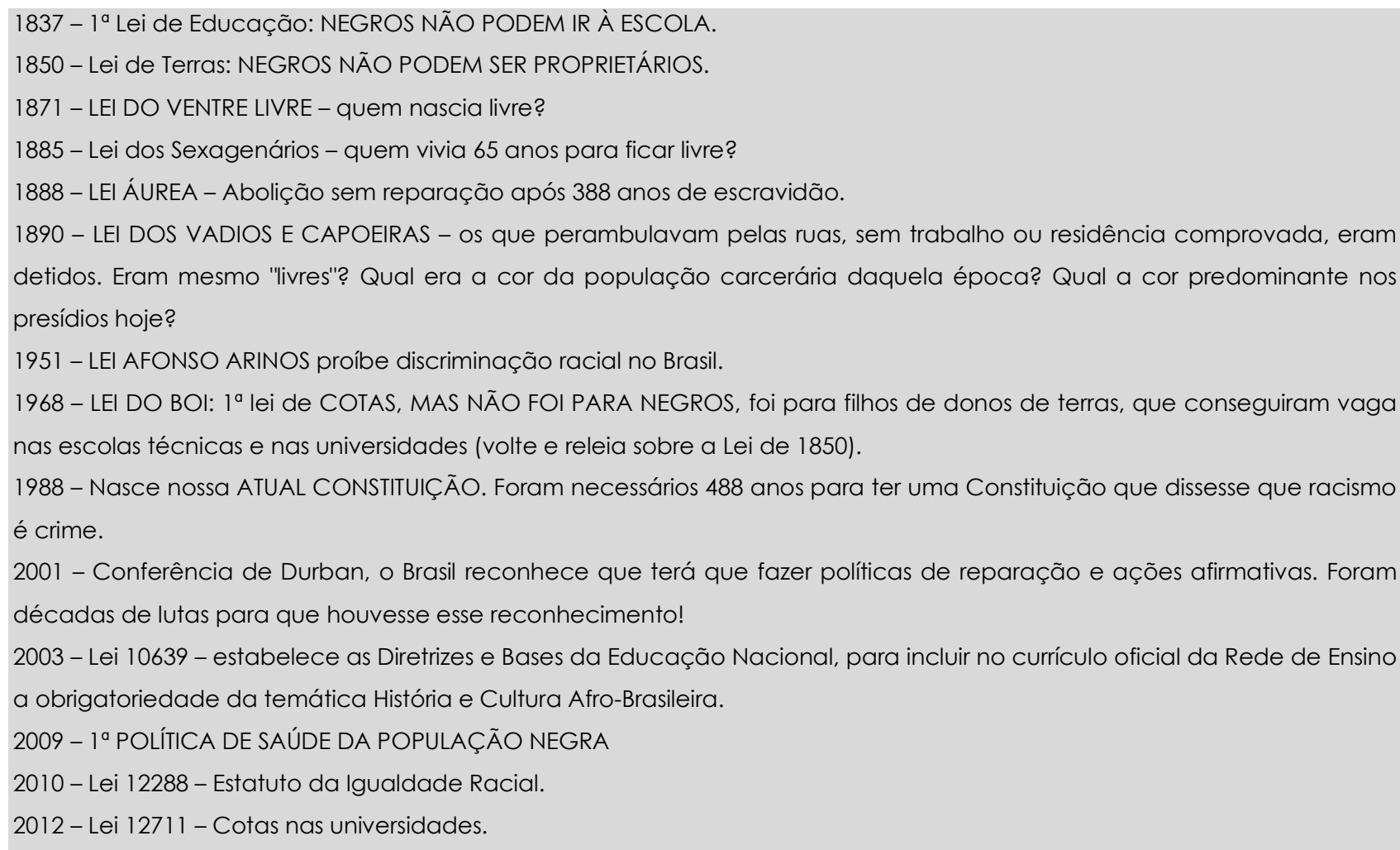

Fonte: Redes Sociais

Tão simples e enriquecedor teria sido, numa das dezenas de apresentações do Exercício Memoriando, que um dos sujeitos tivesse recorrido a uma objetiva linha de tempo que fosse, minimamente para (se) situar quanto ao desrespeito a que temos sido submetidos historicamente.

\footnotetext{
7 In: MARQUES, Zoraya Maria de Oliveira. Questões étnicas raciais no exercício Memoriando: há identidade(s) em conflito ou o silenciamento de si? . Anais do V Congresso Baiano de Pesquisadores Negros, v. I, p. 22-26, 2015.

8 GRUPO WHATSAPP DOCENTE. Linha de Tempo sobre as Leis e a População Negra no Brasil. Postado em 20 de novembro de 2019. Grupo Whatsapp dos Professores do Departamento de Educação.
} 
Ao menos dizer da importância da constituição de 88, ou das lutas pelo reconhecimento das políticas de reparação e ações afirmativas. Sobre a legislação e seus desdobramentos, nada. Silêncio completo. Em todas e cada uma das vezes em que realizamos o exercício.

\section{MAS, NO QUE CONSISTE O EXERCICIO 'MEMORIANDO'?}

É recorrente esclarecer alguns elementos definidores do exercício Memoriando que, em sua etimologia aproxima-se do termo 'memoriale' ou mais conhecido como 'memorial acadêmico' que alguns professores costumam incluir em suas disciplinas, ou que são comuns em cursos lato e stricto sensu, ou até em processos de progressão na carreira universitária, quando é solicitado que o sujeito narre e analise, de forma cronológica, determinados aspectos de sua vida formacional em paralelo às suas principais itinerâncias profissionais.

Neste ponto, costumamos admitir um traço de semelhança, no sentido de que ambas as construções discursivas e auto reflexivas - o exercício Memoriando e o Memorial Acadêmico - supõem uma produção inédita de conhecimento a partir do próprio sujeito, que se volta para si mesmo a fim de narrar e compreender determinados acontecimentos e circunstâncias que vivenciou e que lhe trouxeram experiências e mudanças outras.

Por outro lado, a diferença entre estas duas construções se dão mesmo no território curricular, ou mais precisamente no acolhimento formativo das experiências e acontecimentos que Macedo' vai textualizar como aprendente, fonte autêntica que é da experiência auto formacional.

Vale ressaltar que para construir e apresentar o exercício Memoriando, o estagiário e a estagiária deve reunir, antes de tudo, o maior número de documentos pessoais ao seu alcance, tais como: fotos, convites, cartas, anotações pessoais, bilhetes, diários, agendas, e tudo mais que lhes ajudasse a localizar o(s) acontecimento(s) cujo impacto demandou numa mudança radical em sua existência.

Sempre era recomendado, inclusive, procurar familiares, amigos e até

\footnotetext{
9 MACEDO, Roberto Sidnei. A Teoria etnoconstitutiva de currículo: teoria - ação e sistema curricular formacional. Curitiba: CRV, 2016.
} 
antigos relacionamentos que pudessem thes ajudar neste processo de redescobertas, as vezes difíceis de relembrar. Por tais motivos, seus relatos quase sempre eram carregados de emoção, o que provocava nos colegas espectadores muita empatia e sensibilidade.

Ora as narrativas resgatavam acontecimentos felizes ou traumáticos vividos na infância, ou mesmo dos ritos de passagem comuns na adolescência. Ora traumas ou episódios inesquecíveis, como perdas trágicas em família. Outras se referiam a decisões difíceis de tomar, ou dilemas superados. Algumas que se constituíam em alegrias e feitos extraordinários que marcaram para sempre suas vidas.

Poucas, todavia relatavam ocorrências profissionais, o que se explica por estarem cursando o quinto semestre do curso, e não terem por este motivo estabelecido vínculos profissionais além das práticas de ensino em campo e as visitas diagnósticas para realização do estágio curricular previsto na disciplina para um futuro bem próximo. Como poucos também foram os que compartilharam, como já dito anteriormente, os sulcos e marcas advindas porventura de episódios racistas ou de conflitos étnicos que vivenciaram em suas histórias de vida.

Uma das autoras a que mais recorremos, durante a orientação dos Memoriandos, tem sido Cristine Josso ${ }^{10}$, porquanto ela lida com os acontecimentos formadores sob a perspectiva experiencial que, neste caso, denomina de 'Momento Charneira', estejam estes localizados no âmbito do autoconhecimento, nas questões pessoais ou nos percursos de escolarização.

Em suas palavras, ao se defrontar consigo mesmo e interagir com os demais, o sujeito passa por transformações que tanto podem ser profundas e amplas ou não, quanto de perdas e de ganhos, e é preciso que se interrogue sobre o que fez consigo mesmo para se adaptar, evitar ou mesmo se repetir na mudança e acontecimentos descontínuos que viveu.

Essas situações e fatos transformadores ou 'momentos charneira' como define Josso, são para nós, o âmago do exercício Memoriando, realçados sob títulos relacionais, escolhidos livremente, que à guisa de sínteses são capazes de ajudar os sujeitos a rememorarem suas mais antigas lembranças sem exigências de

10 JOSSO, Marie Christine. Experiências de vida e formação. Lisboa: Educa, 2004. 
lógica temporal nem tampouco de hierarquização de nenhum modo.

Quanto a forma e o conteúdo apresentados nas narrativas, já fomos surpreendidos pela escolha de dispositivos das mais variadas possibilidades, entre os quais: selfs, mapas, pinturas, fotografias emolduradas, espelhos, cartazes e banners, paisagens ilustrativos como cenários de breves dramatizações em monologo, slides e transparências, e até vídeos e trilhas sonoras produzidas especialmente para ilustrar as performances cênicas.

É da experiência pessoal implicada, portanto, que a cena e o assunto escolhido pelo sujeito conduzem esta atividade aos voos formacionais ainda não vividos. A experiência conforme reitera Macedo ${ }^{11}$ não é algo que sucede, é o que nos implica, portanto nos afeta, nos toca, nos mobiliza e também nos impõe, nos compromete.

E, em sendo assim, acreditamos que no exercício Memoriando, algo muda no sujeito, mesmo imperceptivelmente porque em meio ao tudo que permanece.

\section{MEMORIAR ESPREITAVA ‘O QUE’ DO PASSADO, AINDA VIVIA NO PRESENTE}

Muito do que emergiu do exercício Memoriando, e posteriormente foi estudado na pesquisa, não aconteceu de forma planejada. É que, por mais que o sujeito se detivesse nos preparativos para sua apresentação de cinco minutos, as emoções decorrentes das memórias evocadas desvelaram fatos e acontecimentos que, em grande medida, estavam latentes, como a espera de um pretexto para se libertarem das amarras racionais e lógicas.

A observação atenta aos 'não ditos' e aos freios repentinos que, por vezes, ocorriam durante a apresentação, abafados sob comentários do tipo "eu não quero falar muito porque vai me fazer chorar", ou "eu me policiei tanto para não falar sobre isso" e ainda "eu nem sei porque me lembrei disso agora", se tornaram extremamente relevantes para o posterior convite e seleção dos colaboradores entrevistados da pesquisa.

Tanto que, determinadas experiências traumáticas vividas na infância e na adolescência com relação a episódios racistas, quando compartilhadas nas

\footnotetext{
${ }^{11}$ MACEDO, Roberto Sidnei. A Teoria etnoconstitutiva de currículo: teoria - ação e sistema curricular formacional. Curitiba: CRV, 2016.
} 
entrevistas tópicas, revelaram muita revolta reprimida e ressentimentos há muito tempo abafados.

Tanto é, que algumas sessões narrativas terminavam abruptamente assim que as memórias mais doloridas e tristes se avizinhavam, enquanto outras se prolongavam por muito mais tempo do que o previsto, onde as horas escapavam sem que percebêssemos que o agendamento combinado tinha sido descumprido.

Foi por motivos organizativos, e de forma consensuada, que ficou decidido, junto aos sujeitos entrevistados, que as narrativas tópicas que analisaríamos inicialmente, seriam àquelas ocorridas no âmbito escolar.

Tal escolha nos ajudou a selecionar determinados relatos que se destacaram, principalmente, pelas questões étnico raciais marcadas por atitudes preconceituosas e perversas. Para nos acompanhar nas breves análises e compreensões dos três depoimentos que incluímos neste artigo, elegemos Macedo ${ }^{12}$ como interlocutor, a começar pelo sentido atribuído ao termo aprender:

(...)eu não aprendia nada de matemática, por mais que eu tentava não entendia o que a pro falava, até parar de perguntar porque não adiantava de nada perguntar (...) as meninas clarinhas sentavam lá na frente e a pro explicava tudo olhava só pra elas (...) eu cresci achando que aprender era coisa de outro mundo só pra gente bem sabida e branquinha da primeira fila(...) na universidade foi que acreditei na minha capacidade de aprender igual a todo mundo de qualquer cor... [Narrativa Tópica extraída do Diário de Campo].

(...) ir no quadro era um momento de puro terror eu fazia de tudo pra escapar (...)preferia ficar de castigo na direção que ir no quadro (...)me abaixava toda na carteira pra ela não me chamar no quadro olhava a parede fingia que tava copiando no caderno(...) doía demais o jeito que ela me olhava aí eu congelava na hora não nem conseguia pensar (...) seu olhar condenava minha presença, meu cabelo trançado minha cor era a forma que ela tinha de me acusar de não consegui aprender...

[Narrativa Tópica extraída do Diário de Campo].

(...) menino repetente tudo era eu o menino preto da rua sem asfalto que não aprendia nada que batia nos colegas que xingava que pulava a janela pra correr no corredor(...)

que não sabia nada nem tirar a conta do quadro pro caderno, nem meu nome sabia escrever (...)

no dia que eu mar meu primo não ia pra escola não acontecia nada por que não tinha ninguém preto pra ninguém colocar a culpa...

12 MACEDO, Roberto Sidnei. Compreender e mediar a formação: o fundante da educação. Brasília: Liber Livro, 2010.

ODEERE - Revista do Programa de Pós-Graduação em Relações Étnicas e Contemporaneidade. ISSN: 2525-4715 - Ano 2019, Volume 4, número 8, Julho - Dezembro de 2019. 
[Narrativa Tópica extraída do Diário de Campo].

Em Macedo, no que se refere ao fenômeno humano vinculado à própria condição do existir - ao existir, existimos compreendendo e isso implica numa atividade que envolve determinadas condições e possibilidades aprendentes de transformar em realidades significativas para o sujeito, acontecimentos cotidianos da vida, sendo também parte deste cenário de aprendências a deformação.

Quanto tempo, e a que custo emocional, precisou se passar para que estes sujeitos pudessem compreender, sob novas condições e contextos, que nada havia de errado com eles e nem tampouco com a sua capacidade de aprender e de lidar com os desafios inerentes a construção de saberes.

Que o problema e 'deformação' não estava neles e sim nas atitudes preconceituosas e indiferença explícita, com que seus professores das series iniciais conduziam as situações didáticas e relações interpessoais em classe.

Lamentavelmente, tais ocorrências são mais comuns do que pensamos, e não estão restritas a esta ou aquela disciplina, uma vez que são as pessoas, e não os componentes curriculares, que estão impregnadas de sentimentos e atitudes racistas e excludentes.

Que traços identitários de inadequação e inferiorização perduram e quais são superados quando os sujeitos são expostos desde cedo a tais práticas de desrespeito e preconceito? Que impactos desastrosos as suas vidas sofreram e que são difíceis de abandonar, uma vez que o racismo a que foram perversamente expostos deixa marcas difíceis de apagar?

\section{CONCLUIR NÃO É PÔR PONTO FINAL, MAS CONTINUAR NAS RETICÊNCIAS...}

Sem dúvida o Memoriando tem se constituído em mais uma possibilidade didática potente e fecundo exercício formacional. Neste contexto, é possível afirmar que, como dispositivo pedagógico a favor das identidades em conflito, sempre pretendeu dar maior visibilidade e valorização as questões étnicas de origem racial, que estagiários e estagiárias do $5^{\circ}$ semestre porventura estejam enfrentando.

Dentre uma gama de reminiscências e lembranças de infância e adolescência que o exercício ajuda a resgatar, e do esforço de compreensão e 
intercritica que exige dos sujeitos, a experiência do autoconhecimento é provavelmente, a mais relevante das vivências curriculares e epistemológicas que o Memoriando potencializa.

Como pondera Marques ${ }^{13}$ são nas questões que dizem respeito diretamente as etnias raciais, em cenários curriculares e de formação, que as teorias e práticas que têm dado suporte aos conhecimentos que estamos revisitando e ampliando no exercício Memoriando, se mostram capazes de auxiliar que os sujeitos compreendam melhor o que lhes marcou, tanto do ponto de vista construtivo quanto negativamente, propiciando maior abertura de si, se houver disponibilidade e empenho real para a ocorrência de mudanças.

Não que se trate de uma transformação fácil para os sujeitos que entrevistamos. Afinal, determinadas experiências vividas nos primeiros anos de vida são por demais estruturantes, e até desastrosas, para serem abandonadas apenas por conta do desejo e necessidade de superá-las.

Os sujeitos deste estudo, todavia, demonstraram ter consciência de que aprender a mudar (se) requer uma profunda compreensão, contextual e histórica de si mesmos para que, com a maior clareza possível e o mínimo de defensismos, possam refletir e buscar alternativas para lidar de forma saudável com o caráter e a dimensão dos danos que os traumas e frustrações causaram em suas vidas.

Por sua vez, como dispositivo formativo e didático, o exercício Memoriando no âmbito desta investigação de caráter formacional, certamente favoreceu para que este processo de autonomização e empoderamento se impusesse de forma mais urgente, entretanto suas limitações em termos terapêuticos e de continuidade, são dimensões constitutivas que não podem ser ignoradas.

Ao avaliar os alcances da pesquisa até aqui, é licito afirmar que a próxima etapa de teorização precisa estar comprometida com um maior aprofundamento das diversas análises em aberto, que as restrições próprias das reflexões produzidas em textos científicos não podem evitar.

Se por um lado, são complexas e amplas as diversas informações contidas nas entrevistas tópicas que ainda não foram analisadas e que o desafio que se impõe é o de continuar a empreender os movimentos necessários para sua

13 MARQUES, Zoraya Maria de Oliveira. Questões étnicas raciais no exercício Memoriando: há identidade(s) em conflito ou o silenciamento de si? Anais do V Congresso Baiano de Pesquisadores Negros, v. I, p. 22-26, 2015. 
elucidação.

Por outro, não podemos deixar de reconhecer que produzir este segundo escrito pós pesquisa, nos trouxe novo folego e compreensões que estavam latentes e a espera de maior movimentação heurística.

Ademais a busca de autorizar-se a ver por si mesmo, e a querer produzir novos modos de interpretar a própria existência e as experiências formacionais que Ihe dão sentido, se constituem em movimentos crescentes de atrevida autonomização. O que requer tempo e convicção.

Há folego para ambos. A terceira produção que sucederá este artigo o dirá. Até lá, é permitir-se viver as pausas e movimentos inerentes ao reexistir.

\section{REFERENCIAS}

JOSSO, Marie Christine. Experiências de vida e formação. Lisboa: Educa, 2004.

MACEDO, Roberto Sidnei. Compreender e mediar a formação: o fundante da educação. Brasília: Liber Livro, 2010.

MACEDO, Roberto Sidnei. A Teoria etnoconstitutiva de currículo: teoria - ação e sistema curricular formacional. Curitiba: CRV, 2016.

MARQUES, Zoraya Maria de Oliveira. Questōes étnicas raciais no exercício Memoriando: há identidade(s) em conflito ou o silenciamento de si? Anais do $\mathrm{V}$ Congresso Baiano de Pesquisadores Negros, v. I, p. 22-26, 2015.

Zoraya Maria de Oliveira Marques: Professora da Universidade do Estado da Bahia/UNEB. Pós-Doutoramento pela Universidade do Minho/Portugal (2017) e pela Universidade Federal da Bahia/UFBA - Formacce (2010). Doutorado pela Universidade Federal do Rio Grande do Norte/UFRN (2006). Mestrado pela Faculdade de Educação da UFBA/FACED. Pedagoga e Professora Primária. 
(c) $\underset{\mathrm{EY}}{(7)}$ This work is licensed under a Creative Commons Attribution 4.0 International License.

(c) (†) Este trabalho está licenciado com uma Licença Creative Commons - Atribuição 4.0 Internacional.

Artigo recebido para publicação em: Novembro de 2019.

Artigo aprovado para publicação em: Dezembro de 2019. 